\title{
Historiografía de la Fundación de Ciudades en América SIGLO XVI
}

\author{
Historiography Foundation of Cities in America. \\ XVI CENTURY
}

Dra. Marcela Dávalos ${ }^{(*)}$

Resumén: La historia de las ciudades en América Hispana refiere a la construcción de un diálogo sobre el dominio del territorio, tanto como al uso que la historia ha elaborado sobre esas mismas urbes. Las maneras de señalaras y comprenderlas varían desde la conquista hasta la historiografía actual, según el periodo y los autores. Los referentes con que las crónicas explicaron a las urbes americanas distan de los criterios con que las valoraron los autores de los siglos XIX o XX. Y aunque desde la fundación hasta la traza, pasando por las controversias respecto a los grupos indígenas, la presencia de religiosos o las urbes elegidas como capitales y asientos de poder, todos han sido aspectos reiterados a lo largo de la historiografía urbana, sus relatos no son suficientes. La historiografía de las ciudades americanas va más allá que la explicación dada desde la historia-nación; más allá que el progreso, la cuantificación o la riqueza, está la diversidad de prácticas y la construcción de varios mundos.

Palabras-clave: Ciudad hispanoamericana - historiografía colonial - historia urbana.

\begin{abstract}
The history of cities in Hispanic America concerns the construction of a dialogue on control of territory, both as to use that history has made on those same cities. Señalaras Ways and understand vary from the Conquest to the present historiography, according to the period and the authors. The referees explained that chronicles the American cities far from the criteria that the authors evaluated the nineteenth or twentieth centuries. And even from the foundation to the trace, to disputes over indigenous groups, the presence of religious or cities chosen as capital and seat of power, all aspects have been repeated throughout urban history, their stories do not enough. The historiography of American cities goes beyond the explanation from the history-nation beyond that progress, quantification or wealth, is the diversity of practices and the construction of several worlds.
\end{abstract}

Key words: Spanish-american city - colonial historiography - urban history.

(*) Investigadere en Historie en la Dirección de Estudios Históricos INAH. (Instituto Nacional de Antropologia e História) México. E-mail: <mardavalos2001@yahoo.com.mx>. Recebido em 16.11.11 e aceito em 27.02.12. 


\section{Historiografía de la Fundación de Ciudades en América}

\section{SIGLO XVI}

La historia de las ciudades en América Hispana refiere a la construcción de un diálogo sobre el dominio del territorio, tanto como al uso que la historia ha elaborado sobre esas mismas urbes. Las maneras de señalaras y comprenderlas varían desde la conquista hasta la historiografía actual, según el periodo y los autores. Los referentes con que las crónicas explicaron a las urbes americanas distan de los criterios con que las valoraron los autores de los siglos XIX o XX. Y aunque desde la fundación hasta la traza, pasando por las controversias respecto a los grupos indígenas, la presencia de religiosos o las urbes elegidas como capitales y asientos de poder, todos han sido aspectos reiterados a lo largo de la historiografía urbana, sus relatos no son suficientes. La historiografía de las ciudades americanas va más allá que la explicación dada desde la historia-nación; más allá que el progreso, la cuantificación o la riqueza, está la diversidad de prácticas y la construcción de varios mundos.

\section{Ciudad Hispanoamericana — Historiografía Colonial — Historia Urbana}

\section{Historiography Foundation of Cities in America. XVI Century}

The history of cities in Hispanic America concerns the construction of a dialogue on control of territory, both as to use that history has made on those same cities. Señalaras Ways and understand vary from the Conquest to the present historiography, according to the period and the authors. The referees explained that chronicles the American cities far from the criteria that the authors evaluated the nineteenth or twentieth centuries. And even from the foundation to the trace, to disputes over indigenous groups, the presence of religious or cities chosen as capital and seat of power, all aspects have been repeated throughout urban history, their stories do not enough. The historiography of American cities goes beyond the explanation from the history-nation beyond that progress, quantification or wealth, is the diversity of practices and the construction of several worlds.

\section{Spanish-American City — Colonial Historiography — Urban History}

Furtivamente, las ciudades consolidaron la historia de América. Ellas tejieron el puente entre la Península y los nativos que ocupaban las tierras desde Santo Domingo hasta Lima, pasando por Santa Fe de Bogotá, México o Nombre de Dios. El impacto que provocó la existencia de esos imperios ajenos al "Orbis Terrarum", se revela, entre otras muchas cosas, en que los títulos de almirante, virrey y gobernador que se le habían prometido a Colón antes de realizar su primer viaje, le fueron retirados: un capitán no podría poseer mayores extensiones que sus soberanos. A partir del momento en que los navegantes tocaron tierra firme, quedó claro que los siguientes viajes serían de conquista y colonización, ya que aquellos pobladores paganos debían convertirse al cristianismo. Así, la ocupación tomaría forma de "asientos" y ciudades. 
Sin intentar aquí hacer un análisis que reúna a la historiografía de las capitales coloniales en conjunto, creo que es necesario llamar la atención sobre cómo ha sido escrita la historia de la fundación y traza de esas ciudades, en tanto una cosa sería remitirse a comprenderlas desde los textos y diarios de viaje de los cronistas del siglo dieciséis y otra muy distinta analizarla con las fuentes o escritos de autores posteriores y dieciochescos, y otra más interpretarla desde los ojos de los historiadores decimonónicos y del siglo veinte. Mi propósito sólo será enunciar cómo ha sido explicado ese binomio de fundación de ciudades y grupos nativos hispanoamericanos. Y para ello la traza término inusual para el siglo XVI — sirve de guía, no sólo porque remite directamente a los indígenas, sino porque se ha empleado desde distintas ópticas y diferentes épocas.

Más allá de que los puntos de vista sobre las ciudades hispanoamericanas divergen según la época, la interpretación que ha predominado desde hace más de un siglo es la que explica a la capital novohispana desde una perspectiva moderna, es decir, regida por un pensamiento administrativo, económico y demográfico. Sería necesario hacer una revisión minuciosa para cada una de las ciudades y mostrar cómo los letrados anteriores a las Independencias refirieron a la génesis de las ciudades desde criterios tradicionales que quedaron extraviados por el predominio de la versión decimonónica. ¿A qué se debe esto? ¿Por qué para referir a la historia de la traza urbana tenemos como referente obligado la lectura elaborada por los letrados constitucionalistas de los siglos diecinueve y veinte? ¿En qué se funda su autoridad? Sin duda el hecho de que esta pregunta se haya vuelto pertinente tiene que ver con las transformaciones actuales del discurso histórico y en particular con aquella que cuestiona al origen mismo de la disciplina histórica.

\section{1.}

La fundación y la traza son un asunto que las capitales americanas arrastran desde el siglo XVI: de la diseñada por Nicolás de Ovando en 1502 para Santo Domingo hasta la dibujada por Alonso García Bravo para la ciudad de México, pasando por la de 1553 para La Habana; la fundación de Cusco por Francisco Pizarro; la traza de Quito en 1534; la de Lima en 1535 y 1582 o la de Santiago en 1541, todas quedaron impresas por ese modelo urbano que tantas interrogantes ha generado entre los historiadores del siglo XX.

Aunque los documentos del siglo XVI referían a términos como "asientos", "pueblo", "solares" o "calidades", en ocasiones parecen igualarse, no obstante los cinco siglos que llevan encima. Ni las fundaciones, ni las segregaciones raciales, ni la manera de emplear la ciudad, han permanecido inmutables a lo largo de cinco siglos. Es decir, aun cuando la creación de asentamientos se convirtió en un asunto medular que ocupó, y ha ocupado, miles de legajos y textos desde el descubrimiento de América hasta nuestros días, la mirada predominante para comprender ese pasado ha sido la que confeccionaron los nacionalistas decimonónicos y fortalecieron los historiadores del siglo XX, preocupados por el crecimiento y multiplicación de las ciudades.

Pero ¿a qué refieren la traza, la plaza y la fundación? Las explicaciones modernas las han referido como algunas de las múltiples características que rodean a la ciudad: casi siempre se trata de un cuadrángulo en forma de damero con un centro del que, con trazos 
regulares, inician calles perpendiculares que corren hacia los cuatro puntos cardinales; incluye la orientación; la distribución de solares o la buena disposición de sus aires. Los autores contemporáneos también han resaltado el rol de los textos grecolatinos y medievales en los diseños urbanos americanos. La historiografía moderna fue la que resaltó el rol normativo de la traza, aunado a las condiciones geográficas y situaciones poblacionales en las que debía o no realizarse una fundación: desde la abundancia de agua y materiales de construcción; acceso a bosques, tierras cultivables, posibilidad de resguardo, buenos aires, hasta la distancia de los pantanos, han sido aspectos reiterados en esos estudios ${ }^{(1)}$.

La historiografía urbana moderna planteó esas preguntas y las respondió sin percatarse de que su motivación era el asombro que le causaba la explosión de ciudades americanas fortalecida durante la segunda mitad del siglo XX. Desde ahí observó a las fuentes documentales originarias; diferenció a las fundaciones creadas sobre ruinas prehispánicas, las ciudades costeras o las mineras. Fueron los historiadores de la segunda mitad del siglo diecinueve y los del veinte quienes reconstruyeron la mirada de los cronistas; desarrollaron las narraciones sobre la importancia del mar como vínculo entre América y la metrópoli o quienes notaron qué diferenciaba a ciudades asentadas sobre sólidas culturas prehispánicas, como Cusco o Tenochtitlan. De ésta última pregunta surgió la inquietud por la traza: la idea de crear una ciudad sobre las ruinas de un sólido asentamiento indígena, se reflejó en la experiencia de la pobreza, las diferencias socioeconómicas y el boom demográfico y urbanizador.

Desde entonces hasta la actualidad aquellas ciudades han traspasado diversas épocas: la del descubrimiento y las poblaciones; la del asentamiento y aculturación; la de las reformas ilustradas o la de la apropiación de los nacionalismos. Y fue la historiografía urbana del siglo XX la que pulió las preguntas que refieren aún a la gestación, crecimiento y arraigo de las urbes en América, tanto como fue ella misma la que nos permitió distinguir que las ciudades son creaciones sociales y no soportes geográficos ajenos a las colectividades. Así, las inquietudes por explicar la fundación de las urbes en el siglo XVI, generaron una cadena de investigaciones a lo largo del siglo XX. Aquí concentraremos la mirada en cómo

(1) Borah Woodrow, "La influencia cultural europea en la creación de los centros urbanos hispanoamericanos", Ensayos sobre el desarrollo urbano de México, México, SEP-SETENTAS, 1974. p. 66-94; "Aspectos demográficos y físicos de la transición del mundo aborigen al mundo colonial”, Ensayos histórico-sociales sobre la urbanización en América Latina, Buenos Aires, Ed. SIAP, FLACSO, 1978. p. 59-89; SOLANO, Francisco de. Política de concentración de la población indígena: objetivos, procesos, problemas, resultados, Madrid, Separata de la Revista de Indias, ns. 145-146, 1976; Walter Palm Erwin, "Tenochtitlan y la ciudad ideal de Durero", Journal de la Société des Americanistes, 1951, p. 59-66; "La aportación de las órdenes mendicantes al urbanismo en el virreinato de la Nueva España", XXXVIII Congreso Nacional de Americanistas, Stuttgart, 1968; Hardoy Jorge E, "Las formas urbanas europeas durante los siglos XVal XVII y su utilización en América Latina”, Urbanización y proceso social en América, Lima, IEP, Instituto de Estudios Peruanos, 1972, p. 157-190; Morse Richard, "The urban development of Colonial Spanish America", The Cambridge History of Latin America, Vol II, Cambridge University Press, 1984; Miguel D. Mena (Comp), La ciudad colonial del Nuevo Mundo, Formas y Sentidos: Gabriel Guarda, Leonardo Benevolo, Paolo Portoghesi, Erwin Walter Palm, Berlín-Santo Domingo, Ediciones en Jardín de las Delicias, 2001; Miguel D. Mena, Iglesia, espacio y poder: Santo Domingo (1498-1521), experiencia fundacional del Nuevo Mundo, Santo Domingo, Archivo General de la Nación Vol XXX, 2007; Juan Bernal Ponce, Ciudades del Caribe y Centroamérica del siglo XV al siglo XIX, Costa Rica, Editorial Tecnológica de Costa Rica, 1993; Manuel Sánchez de Carmona, Traza y plaza de la ciudad de México en el siglo XVI, México, UAM, 1989; Dr. Franco Fernández Esquivel, La Plaza Mayor. Génesis de la Nación Costarricense, Costa Rica, Editorial Cultural Cartaginesa-Uruk Editores SA, 1996. 
se han explicado las ciudades en las que previamente residía población nativa, en tanto la traza es una clave para seguir el vínculo historiográfico entre la ciudad y los indios.

2.

La fundación de ciudades significó imponerse ante las poblaciones nativas. Luego del reparto de tierras, de la traza en cordel, de las calles alineadas y del resto de las anotaciones dadas por los monarcas, se han derivado nuestras preguntas. A la traza se le ha visto como una frontera - en ocasiones más imaginaria que real — que dividía a las ciudades en dos: en el centro habitarían los conquistadores y en los alrededores los indígenas. Esa traza, que marcó el límite entre el casco y el territorio indio, tanto como el diseño con el que se ordenaron los solares, se ha considerado como un poderoso mecanismo para concretar los procesos de asentamiento y conquista en América: la intensa y sistemática fundación de ciudades en forma de damero, fue una espectacularidad antes no vista. Para el período de 1492 al 1573 - que refiere a una primera etapa "circuncaribe" y a una segunda en que se realizó el contacto con las "culturas prehispánicas urbanizadas" —, las fundaciones tomaron un ritmo vertiginoso: doscientos veintisiete núcleos urbanos se asentaron entre Zacatecas y Buenos Aires ${ }^{(2)}$.

El diseño y finalidad de las fundaciones costeras resultaron ser distintas: en éstas lo prioritario no era congregar o apartar a los indígenas para bien evangelizarlos, sino extraer metales y construir murallas. La orografía y la necesidad de defender las costas impusieron otras reglas, por lo que sus diseños tuvieron mayor parecido a las intrincadas urbes medievales. Desde el norte de México hasta el territorio mapuche diversas revueltas alertaron los frentes y motivaron las fortificaciones. São Paulo, la primera ciudad fortificada, fue fundada como una especie de centro coordinador desde el cual se "entablaban relaciones con los escasos y poco poblados asentamientos. La ciudad en el rol de centro colonizador y base desde la cual internarse y ampliar así la economía colonial, es una tendencia de lo que vendría después. La importancia de la evangelización (justificación para segregar a los indios), también fue referida por los jesuitas para São Paulo. Frei Gaspar se refirió a "questão da desapropiação das terras indígenas, como se estes quisesem nelas de estabelecer". Esto se refleja en la carta que envió a Roma exponiendo las dificultades para los padres de la Compañía de Jesús en convertir a los indígenas a las costumbres cristianas, debido a que la movilidad de los indígenas les creaba serios problemas:

“...Lo que maior dificultad nos haze es la mudanca continua desta gente, que no atura en un lugar sino mui poco, porque como las casas de tierra que usan o de palma no duran sino hasta tres o quatro años, vanse a hazer otras en otro lugar... Esto haze que es necesario gastar el tiempo con poca gente, y ésta quando se han gastados dos, tres años con ella, múdase y piérdese tudo, porque no é gente que persevere si los dexan..."(3).

(2) Francisco de Solano, "Proceso fundacional y perfiles de las ciudades hispanoamericanas", Ciudades Hispanoamericanas y pueblos de indios, Madrid, CSIC-Biblioteca de Historia de América, 1990, p. 25-28.

(3) Janice Theodoro da Silva, São Paulo, 1554-1880. Discurso ideológico e organização espacial, São Paulo, Editora Moderna, 1984, p. 29-30. 
Por su parte, en las ciudades radiales la zona indígena comenzaba donde terminaba la ciudad. Al centro, la plaza reunía la residencia del virrey, al poder religioso, al cabildo y a las casas de los comerciantes principales, mientras que en las calles perpendiculares habitarían el resto de los vecinos. Por los planos y descripciones se sabe que conforme más alejadas de la plaza central, las calles rectas iban disminuyendo, hasta que sus trazos rectos y tirados en cordel desaparecían. Y aunque los indígenas participaban del comercio, servicio y socialización en el casco, la normatividad exigía que regresaran a dormir a sus barrios, práctica que no siempre se mantuvo: esto tiene sentido en tanto la historiografía urbana ha mostrado cómo, luego de tiempos de crisis, rebeliones, tumultos, inundaciones o hambrunas en los que los nativos reaccionaron activamente, los poderes virreinales exigieron que aquel principio de segregación racial se aplicara nuevamente, y con severidad.

Así, el significado de traza como frontera, fue derivado de las anotaciones dadas por los letrados del siglo XVI que fueron testigos - de vista o de oídos - durante el contacto con las tierras conquistadas. Significado que se ha ido activando sucesivamente durante distintos periodos; su historia es de larga duración en tanto el sentido de su existencia ha tenido distintas recepciones y sigue siendo una pregunta vigente. De las Ordenanzas y de los textos de los cronistas se derivaron esas investigaciones preocupadas por la traza y lo indígena. Las preguntas vinieron después, cuando los autores se preguntaron de dónde procedió el diseño de la traza reticular. No se sabe si se trata de un modelo dictado por los europeos o si tiene alguna influencia de las culturas prehispánicas. El acuerdo de que en esas trazas rigió el modelo en damero es indiscutible, pero el consenso se disuelve cuando los autores se preguntan de dónde procedió esa traza reticular. No se sabe si se trata de un modelo dictado por los europeos o si tiene alguna influencia de las culturas prehispánicas. Hay quienes opinan que se trata de una copia de las ciudades del renacimiento italiano, retomado por los españoles y luego importado a América. Hay quien piensa que ese modelo tiene relación con los presupuestos teológicos de Santo Tomás de Aquino, o que las órdenes mendicantes crearon un nuevo modelo de urbanización. Otros autores hablan de una continuidad de las ciudades romanas hasta principios del siglo XVI.

Pero ¿cómo podríamos tomar distancia de la historiografía contemporánea que modeló nuestra manera de interpretar la fundación de ciudades del siglo XVI? ¿Acaso los asientos, la traza o los aires remitieron a una y la misma cosa durante todos esos siglos? Aquellos términos sugieren que los pobladores y conquistadores tenían la mirada puesta en significados distintos, y aunque para responder esto requeriríamos de un gran equipo de investigación, tan sólo quisiera aclarar la idea de cómo, al explicar el pasado desde parámetros contemporáneos, reducimos la posibilidad de mirar otras muchas cosas.

Las primeras indicaciones dadas por Fernando el Católico sobre cómo crear los asentamientos en aquellas tierras desconocidas fueron los cimientos para explicar lo que seguiría después. Una frase cristalizada, escrita por Francisco de Solano, nos permitirá continuar e ir acotando el tema: "estas indicaciones, tan seguidas durante la Edad Media...reverdecieron, o continuaron, en Indias"(4). Una cita tomada de las Instrucciones,

(4) Francisco de Solano, "Proceso fundacional y..., op. cit., p. 37-38. 
dadas en 1513 por Fernando el Católico a Pedrarias Dávila, Capitán General y Gobernador en Tierra Firme, es una muestra de las indicaciones a que refiere Solano:

"...de las más principales cosas en que habéis mucho de mirar es en los asientos de los lugares que allá se hubiere de asentar...cosas que para los asientos de los lugares son necesarias, y escogido el sitio más provechoso y en que incurran más de las cosas que para el pueblo son menester, habéis de repartir los solares del lugar para hacer las casas, y éstos han de ser repartidos según las calidades de las personas, y se han de comenzar dados por orden, por manera que hechos los solares el pueblo parezca ordenado, así en el lugar que se dejase para plaza, como el lugar en que hubiere iglesia, como en el orden que tuvieren las calles... acomodados todos los pobladores, los restantes solares queden para el Rey, que los repartirá o como su merced fuere...si hay riesgo que ataquen los indios cérquese lo poblado con empalizadas" (p.14-16, Durán Montero).

El monarca enlaza entre sí "asientos", "lugar provechoso", "pueblo", "solares", "casas", "calidades" o "plaza". El entorno que fusiona esos términos son los estamentos y las calidades; el orden al que refiere incluye a la iglesia o a la plaza, pero todo aparece delimitando jerárquicamente: los asientos no sólo estarían destinados a los recién llegados, sino que además multiplicarían el orden estamental. Los indios, son mencionados en su relato solamente si hubiese "riesgo de ataque", por lo que la idea de cerca y empalizadas refiere tanto a la experiencia de la reconquista, como a la forma de emplear el espacio para defensa: lo que estaba fuera de la empalizada ya no era la ciudad, sino lo ajeno a los privilegios de quienes residían en la urbe.

Cuando Fernando el Católico dictó las primeras señales sobre cómo debían disponerse los "asientos" o en el momento en que Felipe II mandó las Ordenanzas sobre Nuevos Descubrimientos y Poblaciones de 1573, los monarcas no tenían en mente preguntarse sobre si el modelo de urbe propuesto provenía de Vitrubio, Santo Tomás de Aquino o de Filarete. Además, habría que distinguir las fundaciones iniciales de las Indias Occidentales en la etapa de reconocimiento en el Caribe - La Navidad (1492), Isabela (1492), Santiago (1504) o Santo Domingo (1506) - , de las posteriores que, al toparse los conquistadores con grandes asentamientos, renacieron el sentido de repetir la Reconquista en contra de los moros. Las primeras Instrucciones dadas por el Fernando el Católico, proyectan el desconocimiento y la distancia que el monarca tenía respecto a los recónditos territorios, cuando expresaba que era necesario "hacer algunas poblaciones" y que "de acá no se puede dar en ello cierta forma"(5), es decir, presuponía que los conquistadores, inmersos en su destino, eran quienes legitimarían aquellas posesiones y no, como lo fue después, que las extensas tierras descubiertas se traducirían en una legitimación divina, monárquica y genealógica para los Habsburgos. Las Instrucciones participaban de un pensamiento escolástico y teológico que fue subiendo de tono conforme la expedición rebasó el tono de aventura y fue tomando tintes de reconquista.

Que la expedición a India por Occidente formó parte de universo religioso, se muestra desde que fue Alejandro VI con la Bula Inter Coetera quien repartió lo descubierto

(5) Citado por María Antonia Durán Montero, Fundación de ciudades en el Perú durante el siglo XVI, Sevilla, Escuela de Estudios Hispano-americanos de Sevilla, 1978, p. 12 
entre los Reyes Católicos y los reinos de Portugal. Las expediciones resguardarían para la corona la consolidación de los asentamientos, al tiempo que cubrían una misión salvífica, en contra del paganismo entre los nativos ${ }^{(6)}$. Luego de la derrota de Tenochtitlan los alientos de proseguir la cruzada sólo se detuvieron para atajar el paso a Francia o Inglaterra. Así, desde las Ordenanzas de Carlos V de 1526 hasta las Ordenanzas de Felipe II de 1573, se mandaba a los "virreyes presidentes, Audiencias y gobernadores de las nuestras Indias del mar océano", que cualquier "población" o "pacificación" por descubrir, se hiciera "al servicio de Dios" y se enviara "aviso y relación", antes de "tomar asiento y capitulación".

En esos textos se recordaba, a "los que tienen la gobernación de la Indias, así en lo espiritual como en lo temporal", los pasos que deberían considerar al realizar poblaciones. En esas órdenes estaba implícito que los mandatos se dirigían a los colonizadores, y que el éxito de la expedición dependía de su buena observación sobre los sitios a los que iban llegando. Las observancias sobre los nativos y sus poblados - si eran hombres viejos y mozos de buena complexión; si la comarca era saludable; si los frutos que sembraban eran ponzoñosos, las tierras abundantes, fértiles y de buen clima; si eran o no preferentes los lugares costeros, altos o aireados; etcétera -, eran la guía para orientar a los "descubridores y pobladores". Dos de los apartados de las Instrucciones trasminaron lo referente a la creación de "asientos": "que sean pobladas de indios y naturales a quien se pueda predicar el evangelio pues este es el principal fin para que mandamos hacer los nuevos descubrimientos y poblaciones" y que cualquier asentamiento "tenga buenas entradas y salidas por mar y por tierra de buenos caminos y navegación para que se pueda entrar fácilmente y salir comerciar y gobernar socorrer y defender"(7)

En el siglo XVI, la palabra vecino, de antemano, no incluía a los nativos: "declaramos que se entienda por vecino el hijo o hija o hijos del nuevo poblador o sus parientes dentro o fuera del cuarto grado teniendo sus casas y familias distintas y apartadas y siendo casados y teniendo cada uno casa de por si" ${ }^{(8)}$. Así, el acto de poblar era propio de los conquistadores, quienes debían estar alerta con los indígenas; por ello se les advertía que una vez hecha "la planta de la población y repartimiento de solares", los pobladores tendrían que construir "alguna palizada o trinchera en cerco de la plaza de manera que no puedan recibir daño de los indios naturales...". También se les aconsejaba que además de situar sus "solares y edificios" en la óptima ubicación respecto a "los aires de mediodía y del norte por ser los mejores", colocaran "los edificios de las casas de toda la población" de tal modo que sirvieran "de defensa y fuerza contra los que quisieren estorbar o infectar la población"(9).

(6) Los significados teológicos de la sociedad medieval siguieron vigentes hasta incluso el siglo XVII. Cf. Hartog François, "El testigo y el historiador", Revista Historia y grafía núm. 18, México, UIA, 2002; El espejo de Herodoto, México, FCE, 2009; Alfonso Mendiola Mejía, Bernal Díaz del Castillo: verdad romanesca y verdad historiográfica, México, UIA/ Comisión Puebla-V Centenario, 1991; Retórica, comunicación y realidad. La construcción retórica de las batallas en las crónicas de la conquista, México, UIA-El mundo sobre el papel, 2003; Paolo Grossi, El orden jurídico medieval, Madrid, Marcial Pons, 1996; Françoise Polignac, La naissance de la cité grecque, Paris, La Découverte, 1984

(7) Ordenanzas de Felipe II sobre descubrimiento, nueva población y pacificación de las Indias, 13 Julio de 1573, Francisco Morales Padrón, Teoría y leyes de la conquista, Madrid, Ed. Cultura Hispánica del Centro Iberoamericano de Cooperación, 1979 , p. 489-518.

(8) Cf. Ordenanzas de Felipe II sobre descubrimiento..., op.cit., Nueva población y pacificación de las Indias, 13 Julio de 1573, Punto 128

(9) Ibid., Punto 133. 
La palizada o trinchera era para prevenir levantamientos por parte de los naturales. Por eso en las Instrucciones se añadía que "si los naturales se quisieren poner en defender la población, se les debe dar a entender como se quiere poblar allí no para hacerles algún mal ni tomarles sus haciendas sino por tomar amistad con ellos y enseñarlos a vivir políticamente y mostrarles a conocer a Dios y enseñarles su ley por la cual se salvarán dándoseles a entender por medio de los religiosos y clérigos y personas que para ello disputare el gobernador y por buenas lenguas y procurando por todos los buenos medios posibles que la población se haga con su paz y consentimiento y si todavía no lo consintieren habiéndoles requerido por los dichos medios diversas veces los pobladores hagan su población sin tomar de lo que fuere particular de los indios y sin hacerles más daño del que fuere menester para defensa de los pobladores y para que la población no se estorbe"(10)

Así, esos documentos del siglo XVI refieren a los poblamientos en América en términos de exclusión, nativos, predicación, comercio, cruzada, peligro y repliegue. Una lógica que remite más a una guerra santa que a una disputa por acumulación de capitales. Del mismo modo, podemos deducir que al momento de redactar esos documentos, las inquietudes por saber si las instrucciones para poblar provenían de los preceptos analizados por Santo Tomás de Aquino o del modelo dictado por las urbes renacentistas, estaban lejos. Los pobladores, más bien temerosos, buscaban cómo asentarse en un mundo parecido al suyo, el cual construirían aunque debieran "hacer menos daño" mientras "fuera menester" para su defensa. Así se explica que las Instrucciones refirieran a que, mientras se construía la ciudad, distanciaran a los indígenas: "no se les dejará entrar en la ciudad" hasta estar hecha y "puesta en defensa", con el fin de evitar ataques y también para que los indios vean la ciudad ya terminada y les "cause admiración". Así verían el poder de los conquistadores, capaces de organizar una ciudad, por lo que les respetarían y verían su voluntad de permanecer, de dominar el territorio"(11)

Los indígenas resultaban amenazantes. La preocupación central de los pobladores era cómo permanecer en "asiento" y no "de paso", en esas tierras que les resultaban desconocidas. La evasión, discreción, alejamiento y resguardo estaba presente en los consejos dados en las Instrucciones:

"Entretanto que la nueva población se acaba los pobladores en cuanto fuere posible procuren de evitar la comunicación y trato con los indios y de no ir a sus pueblos ni divertirse ni derramarse por la tierra ni que los indios entren en el circuito de la población hasta la tener hecha y puesta en defensa y las casas de manera que cuando los indios las vean les cause admiración y entiendan que los españoles pueblan allí de asiento y no de paso y los teman par ano osar ofender y respeten para desear su amistad en comenzándose a hacer la población el gobernador reparta alguna persona que se ocupe en sembrar y cultivar la tierra de pan y legumbres de que luego se puedan socorrer para sus mantenimientos y que los ganados que metieren se apacienten en parte donde estén seguros y no hagan daño en heredad ni cosa de los indios para que asimismo de los susodichos ganados y sus crías se puedan servir y socorrer y sustentar la población".

(10) Ibid., Punto 136.

(11) María Antonia Durán Montero, Fundación de ciudades en el Perú durante el siglo XVI, Sevilla, Escuela de Estudios Hispano-americanos de Sevilla, 1978, p. 16. 
3.

De construir "empalizadas" para defenderse de los indios a construir murallas, hubo un salto cualitativo. Para los siglos XVII y XVIII los asentamientos habían alcanzado rangos de ciudad, poblado, villa o lugar. La disputa por los territorios americanos entre España y Francia durante los reinados de Carlos V (1518-1556) y los monarcas galos Francisco I (1515-1547) y Enrique II (1547-1559), provocaron fortalecer tanto la idea de muralla, como la fortificación misma. Y aunque la experiencia ya había gestado varias murallas — la de Cuba en 1540 o las de Cartagena de Indias de 1560 —, para el siglo XVII la relación con la separación entre la ciudad y las zonas indias comenzó a cambiar. La situación estaba varios pasos más allá del tiempo de las "empalizadas" que previnieron a los pobladores de probables ataques indígenas; ahora estaban frente a las costas continuos asaltos a las islas de las Antillas. Pero además de aquella amenaza, los piratas - y sus fantasmas - emergieron sublevaciones en ciudades internas que también alertaron sobre el papel que debían jugar las murallas como defensa.

Antes de los motines, es importante subrayar que en esas ciudades pre-modernas, el papel de las murallas era tanto relevante como elemento de prestigio ${ }^{(12)}$. Las murallas fueron el "hecho constitutivo" de las ciudades: "...aún a principios del siglo XVIII, la muralla y el recinto cerrado, y también la antigüedad, son lo que hace a una ciudad"(13). Un ejemplo tomado del texto escrito en 1622 por Gil González Dávila para la ciudad de Madrid habla más que mil palabras:

“...representa sus murallas, en la antigüedad que tienen, ser fuertes....que dio ocasión a [que] Ruy González Clavijo, Camarero del rey don Enrique III y su embajador en la corte del Gran Tamorlan de Persia... dijese...El rey mi señor tiene una villa en España, que se llama Madrid, cercada de fuego, por el material de que consta su muralla..."(14).

El texto anterior, escrito en el siglo XVII, revela que antes de que criterios económicos rigieran la organización del tiempo y espacio urbanos, las ciudades eran concebidas como sinónimo de Corte, de asiento del imperio real, de criterio de exclusión, o de centros de difusión cristiana. Asimismo, su antigüedad, además de la fortaleza de sus murallas, el poderío de sus campanas o la capacidad para resguardar a sus moradores, eran claves para referir a su importancia. Desde esta óptica escribió José Antonio de Villaseñor su Suplemento al Theatro Americano en el año de 1755. La ciudad es admirada en términos de jerarquías, en función de los edificios religiosos así como del orgullo

(12) En la primera parte de su libro, escrito en el siglo XVII, Gil González Dávila nos deja un hermoso ejemplo: "Una parte de los muros, que mira hacia el mediodía, y se derribó cuando se edificaron los Palacios del Duque de Uzeda y Marqués de Pouar, es obra Romana, cuando mandó derribar los muros de toda España, no se ha de entender que los arrasó del todo, sin que puso por el suelo lo más fuerte, y de lo flaco una parte, sobre la cual los Moros edificaron murallas para conservar el señorío de la tierra; y estos mismos aumentaron nuestro Reyes Castellanos, cuando ganaron a España. Y así, para mí, es muy cierto, que en la muralla de la villa de Madrid tuvieron parte los Romanos, Godos, Moros y los Reyes de Castilla." Cf. Gil González Dávila, Teatro de las grandezas de la villa de Madrid, Madrid, 1622, p. 10-11.

(13) Bernard Lepetit, Las ciudades en la Francia Moderna, Instituto Mora, México, 1996, p. 19.

(14) Gil González Dávila, op. cit., p. 13. 
de los oficios que desempeñaban sus moradores. Esto no es difícil de adivinar luego de leer los elogios que dirige a los reyes católicos quienes, explica el autor, tenían derecho a las riquezas y a los bienes del nuevo imperio descubierto, debido a su "cristiandad eximia". En su discurso las poblaciones, aptas para expandir la cristiandad al Nuevo Mundo, son comparadas, en términos positivos, a los presidios:

"...le ha ido franqueando la soberana liberalidad del altísimo a la corona de nuestro católico rey...mas solo los presidios siempre cuestan y están costando, nada producen para la corona y poco adelantan ni avanzan en los territorios, y sólo son útiles para abrigo mientras las poblaciones toman cuerpo...y con las poblaciones llegan a no necesitarse acabándose la necesidad de su manutención..."(15).

En el siglo diecisiete también fue construida la muralla que circundó Lima. Y aunque "el motivo declarado de esta obra habría sido la defensa militar contra los temidos piratas que acosaban las costas del Pacífico sudamericano", se atribuyó a su débil construcción "una función protectora de las invasiones indígenas que caracterizaron las primeras décadas inmediatamente posteriores al establecimiento de las ciudades hispanas en América"(16).

Que las murallas fueron un elemento defensivo, se complementa con las críticas del holandés Hugo Grocio ${ }^{(17)}$, quien en el capítulo XII del tratado De Iure Praede, polemiza contra la donación papal de los mares y tierras incógnitas - es decir, con la Bula Inter Coetera. En un diálogo directo con las experiencias históricas previas, él abogó porque la base legal que justificara el establecimiento de los pueblos en Ultramar fuera efectiva y no por donación pontificia; con él estaban puestas las bases sobre el derecho a las posesiones americanas. Sería el derecho natural y no las viejas concepciones teocráticas, el que regularía las relaciones entre las naciones y los pueblos.

Ese momento explica la construcción de numerosas fortificaciones amuralladas en Cartagena, Santo Domingo, Veracruz o Campeche. Campeche, punto siempre vulnerable desde la carrera de Indias, sufrió repetidos asaltos en el siglo XVII. En la primera mitad, fue atacado por piratas franceses, holandeses e ingleses: la riqueza maderera y la región agrícola constituyó el más importante puerto de la capitanía general de Yucatán, rivalizando con la capital, Mérida, en el terreno mercantil y económico. Campeche era el mejor astillero de América por sus maderas. El proyecto de fortificación escrito por Martín de la Torre, Discurso sobre la Fortificación de Campeche (1680) decía que "los lugares sin fortificación son como cuerpos sin alma". Cabildo, obispos, gremios, orden franciscana, etcétera, habían aportado cantidades para la ejecución de la muralla ${ }^{(18)}$; proyecto que se terminó realizando hasta el siglo dieciocho.

(15) José Antonio de Villaseñor, Suplemento al Theatro Americano, México, UNAM, Facsimilar de 1755, 1989.

(16) Gabriel Ramón Joffré, La muralla y los callejones. Intervención urbana y proyecto político en Lima durante la segunda mitad del siglo XIX, Perú, SIDEA/Prom Perú, 1999, p. 74-75.

(17) Entre otros muchos textos Hugo Grocio escribió Sobre las Indias (1604-05); Sobre el poder de los soberanos en materia de asuntos religiosos (1614); Disertación sobre el origen de los pueblos de América (1642).

(18) José Antonio Calderón Quijano, op.cit., p. 124. 
Las ciudades importantes del interior, aunque no fueron atacadas por piratas, participaron de esa tendencia a amurallar. Al temor de los corsarios se añadió la expectativa de las sublevaciones indígenas. El siglo XVII también abrió un periodo de revueltas que pondría en cuestión la validez de aquella separación racial. Los motines de 1624 y del 1692 en Nueva España, causados por la escasez del maíz, terminaron en toques de queda luego de que los indios incendiaron los puestos de la Plaza Mayor, robaron mercaderías de tiendas y almacenes o destrozaran partes del Palacio virreinal o del Cabildo ${ }^{(19)}$. Luego de ser apresados, castigados o enviados a servicios forzados, los indígenas debieron replegarse hacia sus barrios. Entre la lista de prohibiciones, que iban desde la imposibilidad de que grupos mayores a tres personas se reunieran en público hasta prohibir que los indios vistieran como españoles, los funcionarios revivieron el asunto de la separación racial ${ }^{(20)}$. Y entonces salieron nuevamente a la superficie los temas derivados de las "empalizadas", que en el siglo XVII cambiaron su tono a muros y murallas.

La historia comenzó a releerse, pero desde otro vértice. Carlos de Sigüenza y Góngora, luego del motín de 1692, se dirigió a los cronistas para justificar la historicidad que tenía la separación racial de la ciudad, a resaltar la importancia de amurallar y a demostrar que sí debía llevarse a la práctica, tal como "lo que ejecutó el Marqués del Valle cuando después de su debelación y conquista reedificó esta ciudad". Para hacer más creíble su palabra remitía a las fuentes anteriores:

“...que fuese esto lo dicen los historiadores de la manera siguiente: Antonio de Herrera...trajo la ciudad, repartió los solares entre los conquistadores y el cuartel de los castellanos puso aparte. Fray Juan de Torquemada en su Monarquía Indiana: esta ciudad está ahora fundada y constituida en el riñón y medio de lo que antes era población de los indios de este primer barrio, llamado Tenochtitlán; no se mezcla esta ciudad con los indios, pero cércanla por sus cuatro partes, haciendo barrios por sí, que son los arrabales de dicha ciudad. Francisco López de Gómara en su Conquista de México: trazó el lugar, repartió los solares entre los conquistadores y mandó que el barrio de españoles fuese apartado del barrio de los indios, y así los ataja el agua. Casi lo mismo dice Bernal Díaz del Castillo al fin del capítulo 170 de su Historia, y en todas las de aquel tiempo y del mismo asunto se lee lo propio"(21).

Aquí la separación racial de los tiempos de la empalizada había rebasado el temor de los pobladores. Las ciudades, construidas y reglamentadas por las Leyes de Indias, al tiempo que las corporaciones y gremios funcionaban en una ciudad ya no de tiendas, sino de construcciones sólidas, habían ganado el derecho a ordenar; así la "separación racial" se traducía en sacar a los indios de los cascos y marcar los límites. En este periodo

(19) Cf. Gibrán I . Bautista, "Los indios y la rebelión de 1624", en Felipe Castro (Coord), Los indios en las ciudades, México, UNAM-IIH, 2010; Natalia Silva Prada, La política de una rebelión. Los indígenas frente al tumulto de 1692 en la Ciudad de México, México, Colegio de México, 2007.

(20) Edmundo O'Gorman, refiriéndose a la ciudad de México asentada sobre Tenochtitlan, fue el que derivó el asunto de la traza hacia la "separación racial". En sus trabajos él se preguntaba sobre los motivos militares, religiosos y políticos por los que los indígenas fueron apartados del casco español. Cfr. "Reflexiones sobre la distribución urbana colonial de la ciudad de México”, Boletín del Archivo General de la Nación, México, vol. IX, núm. 4, 1938, p. 787-815.

(21) "Sobre los inconvenientes de vivir los indios en el centro de la ciudad", Boletín del Archivo General de la Nación, Tomo IX, Enero-febrero-marzo 1928, n. 1, México, p. 6. 
las trazas ya estaban bien definidas: el centro o casco polarizaba con los barrios indígenas. No obstante, la preocupación central tampoco fue definir los referentes culturales de la traza, sino hacerla efectiva. Se trató, más bien, de afinar sus límites, de aclarar administrativamente quiénes vivían dentro y quiénes fuera de ella y, sobre todo, cómo podría hacerse efectivo el principio de segregación, a pesar de que los indios debían asistir a la ciudad (casco o centro), a ofrecer servicios, abastecer de alimentos y cubrir una larga lista de necesidades para los españoles y mestizos.

Yucatán, en 1644, intentó ser fortificada y en México, aunque se habló de cons-

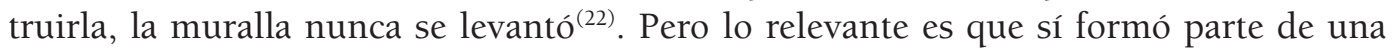
percepción cultural, que ha sido explicada por motivos de defensa militar, religiosos, de policía o económicos, en fin, su papel ha sido fundamental. Así la expresión "más allá de los muros" de la ciudad, implica que el uso de la muralla marcaba al territorio en términos de exclusión - por calidades, estamentos, u oficios —, expresión que aún tenía vigencia hacia finales del siglo dieciocho ${ }^{(23)}$. Adelantándonos un poco en el tiempo, a fin de contrastar lo anterior, es importante señalar que para finales del siglo diecinueve las palabras ciudad, muralla, arrabal y barrio, estaban disociadas. Un año antes de que empezara el siglo veinte, barrio significaba "cada una de las partes en que se dividen los pueblos grandes", en tanto que los arrabales eran "barrios fuera del recinto de la población a que se pertenece; cualquiera de los sitios extremos de una población; una población anexa a otra mayor" y la ciudad era una "población comúnmente grande que en lo antiguo gozaba de mayores preeminencias que las villas"(24). Así, el significado de murallas y barrio nos remite a la función que han tenido ambos sujetos según el periodo de que se trate, es decir, no es lo mismo hablar de un barrio de indios establecido fuera del casco al iniciar las Independencias, que hablar de barrios cuando aún las órdenes regulares eran las que administraban los asentamientos indígenas. El significado de traza, segregación y barrio indígena depende de su función, del uso que se le daba en relación con el conjunto orgánico de la ciudad. Por esto creo es que es obligatorio ubicar las perspectivas desde donde se ha tratado de explicar la traza, desde un enfoque distinto al aportado por los autores de los siglos diecinueve y veinte y distanciarnos así de lo dicho desde los parámetros que les designaron los valores propios del Estado-nación.

4.

Fue la tradición hispana la que bautizó con el nombre de ciudad (o casco) al espacio designado para habitación de los descubridores; asimismo fue ella quien denominó barrios, parcialidades o pueblos de indios a la periferia circundante. De la misma mane-

(22) George Kubler señala que "una variación mexicana muy peculiar" fue la "costumbre de dejar la ciudad abierta y por el contrario fortificar los templos... El modelo de pueblo no amuralladado y la iglesia fortificada tiene antecedentes en la práctica de los mendicantes de la Edad Media", op. cit., p. 100.

(23) Sobre este punto cf. Bernard Lepetit, "La noción de ciudad: su evolución (1650-1850) en los cuadros y descripciones geográficas de Francia" en Las ciudades en la Francia Moderna, Instituto Mora, México, 1996, p.19-23.

(24) Diccionario de Lengua Castellana por la Real Academia Española, 13ava. edición, Imprenta de los Sres. Hernando y Cía, Madrid, Año de 1899. 
ra, fue esa tradición de posesión y dominio a través de las fundaciones urbanas, la que narró los motivos por los que la ciudad de México fue fundada por los españoles sobre Tenochtitlan o que Cusco se fundó sobre Coricancha. Fueron los cronistas quienes comenzaron aquellos relatos míticos prehispánicos. Relatos que se han recreado a lo largo de los siglos, ajustando sus interpretaciones a las necesidades de cada época (de las disputas por los indígenas entre los cleros regular y secular a la secularización arzobispal; del folklor indígena decimonónico a los nacionalismos incluyentes; de la extinción de las culturas nativas al rescate antropológico; de indígena adaptado para el turismo al discurso de las minorías y así sucesivamente hasta llegar a las actuales propuestas del muticulturalismo $\left.{ }^{(25)}\right)$.

Los cronistas fueron los primeros que comenzaron a hablar de la segregación racial. Ellos germinaron las narraciones sobre los augurios que habían motivado a los indios a fundar Tenochtitlan; quienes dijeron que Cusco se levantó sobre la antigua Qosqo o que refirieron a las profecías de Huayna-Capac en Quito. Ellos fueron la fuente de la que surgieron todas las subsecuentes interpretaciones. Y de ellos abrevaron todos los autores posteriores; sin excepción, los cronistas han sido tomados como documentos de primera mano para suponer cómo fueron los poblamientos antes de la conquista. Sus relatos iniciaron esas historias sobre las antiguas ciudades prehispánicas; antes de sus descripciones ningún documento había referido — valga la redundancia - a ciudades prehispánicas o prelusitanas.

La misma idea de llamar ciudades a los emplazamientos indígenas ha sido puesta en duda. Se ha discutido si sus centros ceremoniales pueden considerarse o no ciudades ${ }^{(26)}$. Sobre esto, algunos autores han planteado la pregunta de la siguiente manera: "¿en qué medida los indígenas americanos habían desarrollado centros urbanos antes de la llegada del hombre blanco"(27). Y aunque Borah es uno de los que argumentan que Tenochtitlan sí fue una ciudad, no deja de resaltar el contraste que hace entre los indígenas y "el hombre blanco": aunque su frase fue emitida en la década de los setentas del siglo veinte, bien podría leerse como un contraste entre civilizados y "casi" incivilizados. Sin entrar por el momento en más detalles, señalemos que por un lado están los autores que buscan estrictamente los orígenes de la traza en las tradiciones europeas y por el otro quienes piensan que en el trazado en damero existió cierta influencia indígena. De lo que no hay duda es que ningún autor ha sostenido que los elementos propios de la ciudad colonial en damero fueron cien por ciento de influencia indígena ${ }^{(28)}$.

(25) El multiculturalismo se halla inmerso en las discusiones historiográficas contemporáneas. Considerando los distintos contextos de emisión desde los que se han analizado y comprendido "lo indígena", Guy Rozat hace una revisión que va desde el historicismo hasta la historia cultural. Los indígenas explicados por el nacionalismo decimonónico poco o nada tienen que ver algunos historiadores que, desde finales del siglo veinte permearon sus fronteras con otras ciencias sociales como la antropología o la lingüística. Lo indígena, se construye así desde sus distintos presentes. Guy Rozat, "El multiculturalismo y las ambigüedades de la memoria colectiva" (Manuscrito facilitado por el autor).

(26) Jorge E. Hardoy, Ciudades precolombinas, Buenos Aires, Ediciones Infinito, 1964.

(27) Borah Woodrow, "Aspectos demográficos", op. cit., p. 59.

(28) Hardoy Jorge E., Ciudades precolombinas, Buenos Aires, Ediciones Infinito, 1964; Hardoy Jorge E. y Carlos Tobar, La urbanización en América Latina, Buenos Aires, Editorial del Instituto, 1969; Calneck Edward E., "The internal structure of cities in America pre-columbian cities: the case of Tenochtitlan", Urbanización y proceso social en América, Lima, IEP, Instituto de Estudios Peruanos, 1972, p. 347-358; Caso Alfonso, "Los barrios antiguos de Tenochtitlan y Tlatelolco", 
¿Qué hay detrás de la pregunta de si las ciudades en América nacieron con la llegada de los conquistadores, o si los hábitats precolombinos ya eran ciudades? ¿A qué nos lleva una u otra respuesta? ¿Qué importancia tiene afirmar si los nativos precolombinos conocían o no la traza en damero? ¿Qué hay detrás de la duda de si la forma de los asentamientos indígenas habían o no influido en la traza occidental? ¿Por qué se duda que los indígenas hubieran podido vivir en ciudades? Y si nos adherimos a la idea de que fueron los europeos los promotores de dicho modelo y que los indígenas no lo conocían ¿qué denotaría?

Detrás del interés por conocer si antes de la conquista existían ciudades, si estaban o no diseñadas en damero; si estaban trazada con calles paralelas y un centro, se esconde el deseo de conocer el grado civilizatorio alcanzado por una sociedad. Porque a la ciudad, por axioma, se le asocia con civilización, y a sus habitantes con civilizados. No a cualquier "campamento gitano" la historia lo ha considerado ciudad; para serlo, se le exigen atributos. No es lo mismo ser pueblo, que lugar o villa. Hasta mediados del siglo dieciocho, ser ciudad implicaba participar de una jerarquía.

Aunque en la historiografía urbana latinoamericana la traza ha tenido diversos usos, uno de los elementos clave ha sido considerar desde ella a las ciudades dentro del "ideal" de perfección. La traza y la plaza han sido el espejo de la manera en la que los hombres se ordenan para convivir. A su disposición se le han atribuido distintas cualidades: lugar de reunión de hombres públicos, temporalidad divina, sitio-fortaleza, salud, higiene, orden y muchas otras. Con la traza la historia ha medido el grado de cultura y desarrollo civilizatorio de las poblaciones, ha sido la vara para medir la idea de progreso.

Quienes se han preguntado si las ciudades precolombinas eran ciudades, quizá en el fondo han querido encontrar rasgos cualitativos que permitan ver ciudades en las formas de habitación nativas. El único gran problema es que se ha terminado por ver entre los incas, aztecas o guaraníes rasgos propios de una cultura terriblemente alejada de la precolombina, que es la nuestra. A los hábitats prehispánicos se les ha medido con el criterio de quien pertenece a una ciudad moderna, regida por las nociones de patria, circulación, acumulación, Estado o riqueza.

Para mostrar que sí eran "ciudades", los autores han empleado dos elementos que, desde finales del siglo XVIII, fueron tomados como nivel para medir el grado de civilización: la población y la superficie. Cuando se hace hincapié en las calles rectas, plazas o características monumentales de los recintos ceremoniales, resalta la preocupación por conocer la cantidad de población y superficie. Diversas investigaciones expresan, de una u otra manera, frases con el sentido siguiente: "es más probable que los autores que sostienen que hubo una gran cantidad de población prehispánica acepten la existencia de un grado considerable de urbanización, que los autores que hablan de pocos habitantes..."(29).

Además de que a las ciudades precolombinas se les aplican criterios civilizatorios, lo más sorprendente es que tales hipótesis se realizan sobre ciudades que fueron prác-

Memorias de la Academía Mexicana de la Historia, México, Ene.-Mar. 1956, p. 7-63; Toussaint M, Gómez Orozco F y Fernández J, Planos de la ciudad de México, México, Instituto de Investigaciones Estéticas-UNAM, 1938.

(29) Borah Woodrow, op. cit., p. 59. 
ticamente destruidas. La ciudad de Cusco, que se dice fue trazada por Pachacútec en las primeras décadas del siglo XV, poseía "un núcleo central político-religioso", del que partían en retícula "cuatro caminos imperiales". Al llegar los españoles la refundaron: "se planteó la división en cuadrícula habitual y se procedió al reparto de solares, el viejo entramado urbano fue poco modificado dado que se encontraron con la dificultad de la existencia de construcciones indígenas". Y añade el autor:

"En realidad las modificaciones se centraron en la construcción de los edificios de los españoles sobre los solares de los edificios incaicos, aprovechando en muchas ocasiones los sólidos muros y cimientos prehispánicos...sobre los muros del Corichanca - Templo del Sol — se estableció uno de los conventos más importantes, el de Santo Domingo, y sobre el antiguo Palacio de Viracocha se asentó la Catedral. Evidentemente no sólo hubo razones prácticas para ello, sino también simbólicas, pues de este modo se cimentaba la religión cristiana sobre la pagana. No obstante, el recuerdo del glorioso pasado siempre estuvo presente..."(30).

Un ejemplo más, dado por un cronista del siglo XVI para la ciudad de México, refiere también a la desaparición de la antigua ciudad precolombina, en aras de su refundación hispana. Fray Juan de Torquemada lo anotó así:

"Mucho de lo que de esta ciudad mexicana hay que decir está ya dicho cuando tratamos de ella en el tiempo de su fundación y crecimiento en su gentilidad...para tratar de ella en este tiempo que es poseída de españoles; porque está tan diferente ahora de como estaba entonces que, sin apartarnos de la verdad, podemos afirmar ser otra muy diferente y no haber quedado de la primera más que el asiento...y la memoria de que en otro tiempo lo fue de otras gentes y naciones, y en sus arrabales indios que pueden decir que son descendientes de aquellos que la poblaron, señorearon, sustentaron y engrandecieron; y aún entre los que han quedado no hay rastro ni señal de edificio ni otra particularidad que en su gentilidad tuviesen, con ser los sitios que ahora tienen los mismos que en su gentilidad eran parte de la ciudad, y haber tenido uno de sus reyes sus palacios y casa en aquella parte y barrio que corresponde a la ciudad... Esta ciudad está ahora fundada y constituida en el riñón y medio de lo que antes era poblazón de los indios de este primer barrio llamado Tenochtitlan..."(31).

Las "ciudades" prehispánicas habían quedado sepultadas, no obstante, la historiografía del siglo veinte polemizó sobre ello. Por un lado estaban los que pensaban que en el trazado en damero hubo influencia indígena y por el otro quienes buscan los orígenes de la segregación racial y de la traza en tradiciones estrictamente europeas (además de quienes han referido a sincretismo, reemplazo, síntesis cultural, interacción, coincidencias o reapropiación). Las diferencias en sus argumentos son cuestión de mayor o menor grado en el énfasis puesto sobre la influencia de la morfología prehispánica en la traza colonial, que de argumentos encontrados, es decir, los argumentos de estos autores matizan los vínculos que hubo entre la estructura urbana colonial y la prehispánica. Para ellos las calzadas en línea recta que partían de la plaza prehispánica, aún cuando a veces

(30) Víctor Mínguez e Inmaculada Rodríguez, Las ciudades del absolutismo. Arte, urbanismo y magnificencia en Europa y América durante los siglos XV-XVIII, Barcelona, Universitat Jaume I, 2006, p. 335-336.

(31) Fray Juan de Torquemada, Monarquía indiana, Capítulo XXVI, p. 408-409. 
refieran a su "imperfecta" ortogonalidad, fueron la base sobre la que se trazó la ciudad española. Frases como "la red de calzadas ya existía con anterioridad a la elaboración de la traza"; "la traza, seguía probablemente las principales arterias y manzanas de la ciudad azteca" (32); "las líneas principales del trazado de la ciudad azteca fueron respetadas y sobre esa base surgió la cuadrícula del México colonial"(33), son comunes en sus intervenciones. Y aunque algunos refieran a la destrucción de los centros prehispánicos, no dejan de lado que la traza colonial se levantó sobre las huellas anteriores, en tanto que otros afirman que las instituciones hispanas engarzaron con una organización náhuatl muy fuerte ${ }^{(34)}$. Considerando la tradición europea, autores como Jorge Hardoy parten de que "el modelo de la ciudad colonial hispanoamericana fue un modelo medieval tardío perfeccionado en España" (35), advirtiendo que el diseño hispánico fue adaptado a las condiciones de las ciudades fundadas por el imperio: las calzadas "señalaban los ejes principales a lo largo de los cuales creció la ciudad alrededor del núcleo original..."(36). Ubican las plazas centrales justo donde se hallaban los centros ceremoniales prehispánicos. En el fondo de todo esto se halla una discusión que tiene que ver con el grado de desarrollo que habían alcanzado las ciudades prehispánicas, e incluso más, si era posible considerarlas ciudades. La mayoría de los autores que defienden la importancia previa de la traza prehispánica, resaltan, implícita o explícitamente, el avance de aquella sociedad, y esto es lo que nos vuelve a recordar que la discusión sobre la fundación de las capitales prehispánicas ha sido reconstruida desde los criterios de las sociedades moderna y contemporánea ${ }^{(37)}$.

(32) George Kubler, Arquitectura Mexicana del siglo XVI, FCE, México, 1982, p. 78.

(33) Jorge E. Hardoy, Ciudades precolombinas, Ed. Infinito, Buenos Aires, 1964, p. 204. En esta misma vertiente se pueden consultar Alfonso Caso, "Los barrios antiguos de Tenochtitlan y Tlatelolco", Memorias de la Academia Mexicana de la Historia, México, Enero-marzo, 1956, p. 7-63; Manuel Toussaint, Federico Gómez de Orozco, Justino Fernández, Planos de la ciudad de México, siglos XVI y XVII. Estudio histórico, urbanístico y bibliográfico, UNAM/Instituto de Investigaciones Estéticas, México, 1938; Woodrow Borah, "Aspectos demográficos y físicos de la transición del mundo aborigen al mundo colonial, en Ensayos histórico-sociales sobre la urbanización en América Latina, CLACSO, Ed. Siap, 1978, p. 59-85 y también "La influencia cultural europea en la creación de los centros urbanos hispanoamericanos", Ensayos sobre el desarrollo urbano de México, SEP-Setentas, México, 1974, p.66-94; Francisco de Solano, "Política de concentración de la población indígena: objetivos, proceso, problemas, resultados", Separata Revista de Indias, n. 145-146, Madrid, 1976; Erwin Walter Palm, "Tenochtitlan y la ciudad ideal de Durero", Journal de la Societe des Americanistes, 1951, p. 59-66; Richard Morse, "The urban development of Colonial Spanish America", The Cambridge History of Latin America, vol. II, Cambridge University Press, 1984; Charles Gibson, Los aztecas bajo el dominio español 1519-1810, SXXI, México, 1967; Sonial Lombardo, "El desarrollo urbano de México-Tenochtitlan", Revista Historia Mexicana, Vol. XXII; Oct.-Dic., n. 2, 1972, El Colegio de México, México, p. 160-187.

(34) James Lockhart demuestra que los grupos nahuas estaban organizados en "altépetl", que funcionaban a modo de "imperios" que se prolongaron a través de los siglos: "Todo lo que los españoles organizaron fuera de sus propios asentamientos en el siglo XVI, la encomienda, las parroquias rurales, las municipalidades indígenas, las jurisdicciones administrativas iniciales, fue sólidamente construido sobre altépetl individuales ya existentes". O bien, "el orden que presenta Tezozomoc es el mismo que seguía funcionando en los siglos XVI y XVII". Cf. Los nahuas después de la Conquista. Historia social y cultural de la población indígena del México central, siglos XVI-XVIII, FCE, México, 1999 , p. 28 y 42.

(35) Jorge E. Hardoy, "Las formas urbanas europeas durante los siglos XV al XVII y su utilización en América Latina" en Urbanización y proceso social en América, Lima Instituto de Estudios Peruanos, 1972, p. 126-127; Antonio Bonet Correa, El urbanismo en España e Hispanoamérica, Cátedra/Ensayos arte, Madrid, 1991.

(36) Jacques Soustelle, La vida cotidiana de los aztecas, FCE, México, 1955, p. 31-33.

(37) Luego de referirse a varios planos realizados por indígenas en los alrededores de 1580, Kubler concluye: "De los principios urbanísticos presentados en estos dibujos pueden deducirse varios rasgos dominantes. Las casas se 
Por su parte, los autores que consideran que la traza novohispana es un modelo europeo traspuesto al Nuevo Mundo, nos remiten a la discusión sobre las ciudades antiguas y medievales. La discusión en primer lugar se deriva de los tipos de plantas hallados en las urbes europeas, ya fuesen irregulares, radiocéntricas o regulares ${ }^{(38)} ;$ y aún cuando aquí no es posible remitirnos a la historiografía urbana europea, es necesario recordar que uno de los acuerdos entre los estudiosos de las ciudades, es el de que el tipo de traza de la capital novohispana fue regular, también llamada en damero, ortogonal o perpendicular. Si el acuerdo básico entre estos autores es que la traza era regular, los desacuerdos surgían sobre dónde, cuándo y cómo se había gestado dicho modelo urbano: los argumentos van de desde decir que "la traza en forma de damero no representaba una invención, sino la mera repetición del sistema usado antes de la Conquista en ambos continentes", hasta la idea de que la plaza europea había sido simplemente desplazada. Las inquietudes por precisar cómo se gestó la traza nos lleva por varias vetas: "hay quien piensa que ese modelo tiene relación con los presupuestos teológicos de Santo Tomás de Aquino, o que las órdenes mendicantes crearon un nuevo modelo de urbanización" (39). Otros autores hablan de la continuidad que hay entre las ciudades antiguas y las de principios del siglo XVI, o bien especulan sobre el vínculo entre las ciudades árabes reconquistadas y las americanas, e incluso se ha dicho que las ciudades hispanoamericanas formaron parte del proyecto utópico europeo que - excepto en contadas ciudades como en Palmanuova, Cádiz (Puerto Real) o Granada (Santa Fe) en las que había sido ya implementado el trazo en tablero — sólo pudo culminarse en América ${ }^{(40)}$.

Pero cualquiera de las posturas anteriores, más que introducirnos a una discusión sobre si los sitios prehispánicos debieran o no considerarse ciudades, nos llevan a reflexionar sobre la función que tuvo esa discusión histórica desde finales del siglo dieciocho

distribuían de acuerdo con un plano en forma de damero, cruzado por dos ejes principales intersectados en ángulo recto. En la intersección se localizaba la plaza pública, de proporciones simétricas, rodeada por edificios uniformes de estilo monumental. Si bien la plaza podía o no estar fortificada, siempre se levantaba al oriente una iglesia grande con aspecto de fortaleza. Ninguna fortificación periférica protegía a la ciudad y sus proximidades se distinguían por la uniformidad y orden de las manzanas. El pueblo se subdividía en distritos o barrios, cada uno con su propio templo. Como un todo, estos pueblos eran distintos a los contemporáneos. Sin embargo, cada uno de los elementos urbanos mencionados tuvo sus antecedentes morfológicos prácticos y teóricos." George Kubler, op.cit., p. 98-99.

(38) Cueca Goitia, coincidiendo con otros autores, parte de tres tipos de ciudades europeas: "el irregular, el radiocéntrico, donde lo más frecuente es que falte la rigidez de la geometría, y el regular, sobre todo cuadriculado o en tablero de damas". Fernando Chueca Goitia, Breve historia del urbanismo, Alianza Editorial, Barcelona, 1985 (Décima edición de 1968), p. 101. Leonardo Benevolo se refiere a las ciudades en retícula en perspectiva simétrica para referirse a las fundaciones españolas coloniales. Cf. Leonardo Benevolo, La ciudad europea, Editorial Crítica. La construcción de Europa, Barcelona, 1993, p. 111-129; cf. Fernando Bonet Correa, op.cit., Pirenne

(39) Cf. Walter Erwin Palm, "La aportación de las órdenes mendicantes al urbanismo en el Virreinato de la Nueva España" en Sonderdruck aus Verhandlungen des XXXVIII. Internationalen Amerikanistenkongresses, Stutgart-München, 12-18 agosto 1968. También Pablo Hermida Lazcano, "Topografía de una utopía: de la Utopía de Tomás Moro a los puebloshospitales de Vasco de Quiroga”, Revista de Indias, vol. LV, núm. 204, Madrid, p. 357-385, Mayo-agosto 1995.

(40) “...hay que reconocer que muchas de las ideas urbanísticas del Renacimiento, que no pasaron de doctrina, utopía o ejercicio ideal del intelecto en los países de Europa donde se originaron, tuvieron su campo de realización real en América en la ingente obra de colonización española". Cf. Fernando Chueca Goitia, op.cit., p. 126-127. En esta línea también se encuentran los trabajos de Luis Weckman, La herencia medieval en México, FCE/Colegio de México, México, 1996, p. 411-424; Francisco de Solano, "La expansión urbana ibérica por América y Asia. Una consecuencia de los Tratados de Tordesillas", en Revista de Indias, vol. LVI, núm. 208, Madrid, p. 614-636, 1996. 
hasta finales del siglo veinte. Desde luego no pretendería afirmar aquí que el mismo discurso se repitió sin cambios durante dos siglos, sin embargo - más allá de que sería necesario dedicar una investigación a aclarar los matices y diferencias entre los periodos contenidos en esos doscientos años - , no es exagerado decir que aquella continuidad revela el tiempo que requirió la historia-nación para consolidarse. Para la historiografía del diecinueve, la cual ha normado hasta hoy la interpretación sobre las urbes, la ciudad fue símbolo de progreso, y éste era cuantificable según la extensión urbana, la cantidad de población, las actividades productivas, los grandes edificios o las fuentes y monumentos contenidos en ella. Pero los atributos que le daban a las urbes los hombres del diecinueve no son los mismos que le asignaron los de los siglos anteriores.

\section{REFERÊNCIAS BibLIOGRÁFICAS}

BAUTISTA Y LUGO, Gibran I. I. Los indios y la rebelión de 1624, en Felipe Castro (Coord), Los indios en las ciudades. Méxic: UNAM-IIH, 2010.

BENEVOLO, Leonardo. La ciudad europea. Editorial Crítica. La construcción de Europa, Barcelona, 1993, p. 111-129; cf. Fernando Bonet Correa, op.cit., Pirenne.

BERNAL PONCE, Juan. Ciudades del Caribe y Centroamérica del siglo XV al siglo XIX. Costa Rica: Editorial Tecnológica de Costa Rica, 1993.

BONET CORREA, Antonio. El urbanismo en España e Hispanoamérica, Madrid: Cátedra/Ensayos arte, 1991.

BORAH, Woodrow. Aspectos demográficos y físicos de la transición del mundo aborigen al mundo colonial. Ensayos histórico-sociales sobre la urbanización en América Latina, Buenos Aires, Ed. SIAP, FLACSO, 1978.

BORAH, Woodrow. La influencia cultural europea en la creación de los centros urbanos hispanoamericanos. Ensayos sobre el desarrollo urbano de México, México, SEP-SETENTAS, 1974.

CALNECK, Edward E. The internal structure of cities in America pre-columbian cities: the case of Tenochtitlan. Urbanización y proceso social en América, Lima, IEP, Instituto de Estudios Peruanos, 1972, p. 347-358.

CASO, Alfonso. Los barrios antiguos de Tenochtitlan y Tlatelolco. Memorias de la Academia Mexicana de la Historia, México, Enero-marzo, 1956, p. 7-63.

CHUECA GOITIA, Fernando. Breve historia del urbanismo. Alianza Editorial, 10. ed. 1968. Barcelona: 1985 (Décima edición de 1968).

D. MENA, Miguel (Comp.). La ciudad colonial del Nuevo Mundo, Formas y Sentidos: Gabriel Guarda, Leonardo Benevolo, Paolo Portoghesi, Erwin Walter Palm, Berlín-Santo Domingo, Ediciones en Jardín de las Delicias, 2001.

D. MENA, Miguel. Iglesia, espacio y poder: Santo Domingo (1498-1521), experiencia fundacional del Nuevo Mundo, Santo Domingo, Archivo General de la Nación Vol XXX, 2007.

DICCIONARIO de Lengua Castellana por la Real Academía Española. 13ava. ed. Imprenta de los Sres. Hernando y Cía, Madrid, Año de 1899.

DURÁN MONTERO, María Antonia. Fundación de ciudades en el Perú durante el siglo XVI. Sevilla, Escuela de Estudios Hispano-americanos de Sevilla, 1978.

FERNÁNDEZ ESQUIVEL, Dr. Franco. La Plaza Mayor. Génesis de la Nación Costarricense. Costa Rica: Editorial Cultural Cartaginesa-Uruk Editores SA, 1996. 
GIBSON, Charles. Los aztecas bajo el dominio español 1519-1810. SXXI, México, 1967.

GONZÁLEZ DÁVILA, Gil. Teatro de las grandezas de la villa de Madrid. Madrid, 1622.

GROSSI, Paolo. El orden jurídico medieval. Madrid. Marcial Pons, 1996.

HARDOY Jorge E. Ciudades precolombinas, Buenos Aires: Ediciones Infinito, 1964.

HARDOY Jorge E; TOBAR, Carlos. La urbanización en América Latina. Buenos Aires: Editorial del Instituto, 1969.

HARDOY, Jorge E. Las formas urbanas europeas durante los siglos XV al XVII y su utilización en América Latina. Urbanización y proceso social en América. Lima: IEP, Instituto de Estudios Peruanos, 1972.

HARTOG, François. El espejo de Herodoto. México: FCE, 2009.

HARTOG, François. El testigo y el historiador. Revista Historia y grafía n. 18, México, UIA, 2002.

JOFFRÉ, Gabriel Ramón. La muralla y los callejones. Intervención urbana y proyecto político en Lima durante la segunda mitad del siglo XIX. Perú: SIDEA/Prom Perú, 1999.

KUBLER, George. Arquitectura Mexicana del siglo XVI. FCE, México, 1982.

LAZCANO, Pablo Hermida. "Topografía de una utopía: de la Utopía de Tomás Moro a los pueblos-hospitales de Vasco de Quiroga”. Revista de Indias, vol. LV, núm. 204, Madrid, p. 357-385, Mayo-agosto 1995.

LEPETIT, Bernard. La noción de ciudad: su evolución (1650-1850) en los cuadros y descripciones geográficas de Francia. En: Las ciudades en la Francia Moderna, Instituto Mora, México, 1996, p. 19-23.

LOCKHART, James. Los nahuas después de la Conquista. Historia social y cultural de la población indígena del México central, siglos XVI-XVIII. FCE, México, 1999, p. 28 y 42.

LOMBARDO, Sonial. "El desarrollo urbano de México-Tenochtitlan". Revista Historia Mexicana, vol. XXII; Oct.-Dic., n.2, 1972, El Colegio de México, México, p. 160-187.

MENDIOLA MEJÍA, Alfonso; Díaz del Castillo; Bernal. Retórica, comunicación y realidad. La construcción retórica de las batallas en las crónicas de la conquista, México. UIA-El mundo sobre el papel, 2003.

MENDIOLA MEJÍA, Alfonso; Díaz del Castillo; Bernal. Verdad romanesca y verdad historiográfica. México, UIA/Comisión Puebla-V Centenario, 1991.

MÍNGUEZ, Víctor; RODRÍGUEZ, Inmaculada. Las ciudades del absolutismo. Arte, urbanismo y magnificencia en Europa y América durante los siglos XV-XVIII. Barcelona, Universitat Jaume I, 2006. p. 335-336.

MORALES PADRÓN, Francisco. Teoría y leyes de la conquista. Madrid: Ed. Cultura Hispánica del Centro Iberoamericano de Cooperación, 1979. p. 489-518.

MORSE, Richard. "The urban development of Colonial Spanish America". The Cambridge History of Latin America, Vol. II, Cambridge University Press, 1984.

O'GORMAN, Edmundo. "Reflexiones sobre la distribución urbana colonial de la ciudad de México", Boletín del Archivo General de la Nación, México, vol. IX, n. 4, p. 787-815, 1938.

O'GORMAN, Edmundo (edit.). Sobre los inconvenientes de vivir los indios en el centro de la ciudad. Boletín del Archivo General de la Nación, Tomo IX, Enero-febrero-marzo 1928, n. 1, México, p. 6.

ORDENANZAS de Felipe II sobre descubrimiento, nueva población y pacificación de las Indias, 13 Julio de 1573. Disponible en: <http://www.biblioteca.tv/artman2/publish/1573_382/Ordenanzas_de_Felipe_II_sobre_descubrimiento_nueva_1176.shtml > 
PALM, Erwin Walter. La aportación de las órdenes mendicantes al urbanismo en el virreinato de la Nueva España. Stuttgart, 1968.

PALM, Erwin Walter. "La aportación de las órdenes mendicantes al urbanismo en el Virreinato de la Nueva España". En: XXXVIII Congreso Nacional de Americanistas (Internationalen Amerikanistenkongresses, Stutgart-München), 12-18 agosto 1968.

PALM, Erwin Walter. Tenochtitlan y la ciudad ideal de Durero. Journal de la Société des Americanistes, 1951.

POLIGNAC, Françoise. La naissance de la cité grecque. Paris: La Découverte, 1984.

PRADA, Natalia Silva. La política de una rebelión. Los indígenas frente al tumulto de 1692 en la Ciudad de México. México: Colegio de México, 2007.

ROZAT, Guy. El multiculturalismo y las ambigüedades de la memoria colectiva. (Manuscrito facilitado por el autor)

SÁNCHEZ DE CARMONA, Manuel. Traza y plaza de la ciudad de México en el siglo XVI. México, UAM, 1989.

SILVA, Janice Theodoro da. São Paulo 1554-1880. Discurso ideológico e organização espacial. São Paulo, Editora Moderna, 1984, p. 29-30.

SOLANO, Francisco de. La expansión urbana ibérica por América y Asia. Una consecuencia de los Tratados de Tordesillas. En: Revista de Indias, v. LVI, núm. 208, Madrid, p. 614-636, 1996.

SOLANO, Francisco de. Política de concentración de la población indígena: objetivos, procesos, problemas, resultados. Madrid, Separata de la Revista de Indias, n오 145-146, 1976.

SOLANO, Francisco de. Proceso fundacional y perfiles de las ciudades hispanoamericanas. Ciudades Hispanoamericanas y pueblos de indios, Madrid, CSIC-Biblioteca de Historia de América, 1990.

SOUSTELLE, Jacques. La vida cotidiana de los aztecas. FCE, México, 1955.

TORQUEMADA, Fray Juan de. Monarquía indiana. Capítulo XXVI, p. 408-409 (completar referencia)

TOUSSAINT M, Gómez Orozco P.; FERNÁNDEZ J. Planos de la ciudad de México. México: Instituto de Investigaciones Estéticas-UNAM, 1938.

TOUSSAINT, Manuel; GÓMEZ DE OROZCO, Federico; FERNÁNDEZ, Justino. Planos de la ciudad de México, siglos XVI y XVII. Estudio histórico, urbanístico y bibliográfico, UNAM/Instituto de Investigaciones Estéticas, México, 1938.

VILLASEÑOR, José Antonio de. Suplemento al Theatro Americano. México, UNAM, Facsimilar de $1755,1989$.

WECKMAN, Luis. La herencia medieval en México. FCE/Colegio de México, México, 1996, p. 411-424. 